\title{
HISTORIA DEL DERECHO, ¿PARA QUÉ?
}

\author{
Ana Brisa Oropeza Chávez \\ Universidad Anáhuac Veracruz, México \\ https://doi.org/10.36105/iut.2021n33.16
}

\begin{abstract}
Pablo Mijangos (coord.), Historia del Derecho, ¿para qué?, México, Tirant Lo Blanch (Colección: Historia del Derecho en América Latina), 2020, 142 pp. ISBN: 978-841-336-4766.
\end{abstract}

La obra que coordinó el Dr. Pablo Mijangos y González, publicada por la editorial Tirant Lo Blanch recientemente, nació en el seno del Seminario Permanente de Historia del Derecho y la Justicia, cuyos integrantes discutieron alrededor de una pregunta que se ha formulado en diversos tiempos y contextos desde, al menos, los años setenta del siglo pasado. Así lo prueba, en el caso mexicano, el trabajo de María Del Refugio González, quien, en 1977, publicó "La Enseñanza de la Historia del Derecho Mexicano"; ${ }^{1}$ en dichos comentarios elabora un análisis sobre la evolución de la asignatura en México, su importancia en la formación de los abogados y hace algunos apuntes sobre la cuestión alrededor de su metodología. En aquel entonces, la autora mostraba cierto optimismo sobre el futuro de la materia que, en la década de los ochenta tuvo que enfrentar el primer embate de posturas modernizadoras que habrían de culminar con el enfoque del modelo de enseñanza por competencias de la década de los noventa en el que se primó el ejercicio profesional liberal. Prueba de ello lo podemos encontrar en el Boletín del Ilustre Colegio de Abogados de Madrid de marzo de 1988, número monográfico en el que se publicaron a texto completo, las respuestas de diversos profesionales a una Encuesta sobre la Historia del Derecho español, en el marco de la reforma que se hizo al Título de Licenciado en Derecho en aquel país, en la que se proponía que la materia de Historia del Derecho no fuese considerada como

1 González Domínguez, María del Refugio, "La enseñanza de la historia del Derecho Mexicano", Boletín Mexicano de Derecho Comparado, vol. 1, núm. 30, México, 1977, pp. 525-542. 
materia obligatoria. ${ }^{2}$ La totalidad de los encuestados, que iban desde profesores de asignaturas diversas, un notario, un decano del Colegio de Abogados, abogados postulantes, funcionarios, hasta el cierre del importante historiador del Derecho, Alfonso García Gallo, llevaron a cabo una defensa unánime, no solo sobre la importancia de conservar la materia como troncal u obligatoria, sino que elaboraron un verdadero panegírico alrededor de la disciplina y una crítica ácida hacia quienes desdeñaban su valor. Destaco la respuesta introductoria de Ángel Sánchez De la Torre, catedrático de filosofía del Derecho de la Universidad Complutense, quien, con sorpresa frente al planteamiento, que él calificaba de tal modo improcedente que rayaba en la obscenidad, de si los juristas deben conocer la Historia del Derecho, contestaba: “¡Pero si el Derecho es la más preclara de las fuentes escritas de la Historia, es el más antiguo de los objetos de investigación histórica, y es la base metodológica del conocimiento histórico!". La batalla la ganó la asignatura que en España, sigue siendo obligatoria, pero la guerra aún no está terminada. Por circunstancias que admiten diversas explicaciones, ligadas, por supuesto al tiempo histórico, la reflexión profunda, tanto de la utilidad como de la legitimación de la Historia del Derecho-retomando los dos conceptos que Carlos Pereyra exponía en el texto recogido en la obra Historia, ¿Para qué? ${ }^{3}$, en la que se inspiró el título de la obra en comento - se detuvo a finales de la década de los ochenta. Sin embargo, una revisión superficial de la producción historiográfica de los últimos treinta años, nos permite identificar, sí, esa mengua en los estudios especializados alrededor de la Historia del Derecho como objeto de estudio científico, o, dicho de otra manera, pensándose a sí misma, pero también nos muestra que hubo también un cambio en los objetos de estudio tradicionales, cambio que Pablo Mijangos, en otra de sus obras, El nuevo pasado jurídico mexicano, ${ }^{4}$ califica como de modernidad jurídica, que él entiende como una visión que ha intentado superar el tradicional legalismo en los estudios de Historia del Derecho, aunque él mismo admite aún insuficiente, provisional pero, y coincido, innegable. Este cambio de visión, necesariamente nos ha conducido hacia la encrucijada sobre cuál debe ser o es - discusión que me coloca en el terreno de un debate para una tarea posterior - la nueva conceptualización del saber históricojurídico. Así planteado, resulta pues, que los estudios especializados escasearon, aunque, desde luego que los hubo, solo a guisa de ejemplo cito el breve pero representativo ensayo de Viviana Kluger, publicado en 2003 en Argentina y que lleva por título el mismo que la obra que ofrezco a su consideración Historia del Derecho ¿Para qué?; ${ }^{5}$ pero la construcción epistemológica sobre aquella utilidad y la legitimación, se hizo por los historiadores alrededor del desarrollo de sus investigaciones.

Es dentro de este escenario que la obra coordinada por Pablo Mijangos muestra su valía y pertinencia, pues logró reunir a un grupo de profesionales que

2 Encuesta sobre la historia del Derecho español, Boletín del Ilustre Colegio de Abogados de Madrid, Revista Jurídica General, núm. 2, marzo-abril, 1988, pp. 7-24.

Pereyra, Carlos, “Historia, ¿Para qué?”, Historia, ¿Para qué?, 25a. ed., Ed. Siglo Veintiuno, México, pp. 9-31. Mijangos, Pablo, El nuevo pasado jurídico mexicano, Dykinson, Madrid, 2011, p. 83.

Kluger, Viviana, “Historia del Derecho, ¿Para qué?”, Conceptos, 78-1, Buenos Aires, 2003, pp. 13-15. 
han dedicado sus esfuerzos intelectuales al cultivo de la ciencia histórico-jurídica o jurídica-histórica, según como se entienda, quienes nos comparten, a través de textos suscintos e íntimos, esas consideraciones que cada uno ha construido desde sus estudios particulares. Es necesario, además, dejar apuntado que la obra armoniza con esfuerzos intelectuales de naturaleza similar en otras latitudes, pues es el caso que el libro coordinado por José María Pérez Collados, Maneras de construir la historia. La filosofía de los historiadores del Derecho, ${ }^{6}$ fue publicado con una diferencia mínima de tiempo que la obra en comento, lo cual confirma la apreciación de que existe un nuevo aliento en la materia.

Renunciaré a intentar una síntesis, que de cualquier modo sería insuficiente e injusta para una obra que requirió ya un esfuerzo de concreción por parte de cada uno de los participantes e intentaré, en algunas líneas, una exposición meramente informativa que, espero, promueva su lectura y discusión.

Los autores concuerdan en la necesidad formativa de la historia en general, y del Derecho en lo particular, así como de la filosofía, en la preparación de cualquier futuro jurista, tanto por el desarrollo de las habilidades críticas que requerirá, como para ponerlos a salvo de la legolatría y la sumisión a la fuerza del poder político. No es un mero esfuerzo teórico o de vanidad dogmática, esos conocimientos podrán tener una aplicación práctica y concreta, tanto para jueces como para abogados postulantes, en su carácter de averiguadores de la verdad, esa verdad que en un país como México ya sabemos que puede ser manipulada bajo adjetivos tan polisémicos como el de "verdad histórica". Particularmente, encontré también un consenso sobre la oportunidad que los análisis históricos brindan a los abogados para comprender que el Derecho es mutable, cambia en función de los tiempos, los lugares y las sociedades, lo que le brinda al jurista una suerte de inoculación frente a la peligrosa creencia de que la ley de hoy es la ley para siempre, pero también frente a la igualmente amenazadora consideración de que la ley puede y debe amoldarse a cualquier iniciativa o capricho de los operadores político-sociales. Estrada Michel califica nuestra disciplina como "el último reducto erudito que resta en los planes de estudio para la licenciatura abogadil", no sé si es el último, pero coincido en que en más de una ocasión será la única oportunidad para muchos futuros abogados de tener contacto con fuentes primarias y documentos que diseñaron la manera misma en que comprendemos hoy el Estado, sus instituciones, la cultura jurídica y el Derecho que nos rige a todos. Además, la Historia del Derecho abre la ventana a nuevos campos del conocimiento como la ciencia política, la sociología, la filosofía y, como bien señala Claudio Magris, ${ }^{7}$ la literatura. Esclarece, y esto es fundamental, aunque parezca evidente, lo que se ha entendido y entendemos hoy como justicia.

$\mathrm{Al}$ discurrir por las catorce aportaciones de los investigadores participantes, ordenadas por estricto y justo orden alfabético, podemos advertir, primero una reacción hacia la obviedad acerca de la naturaleza formativa de la Historia del

6 Pérez Collados, José María, Maneras de construir la historia. La filosofía de los historiadores del Derecho, Marcial Pons, Madrid, 2020.

7 Magris, Claurdio, Literatura y derecho. Ante la ley, Sexto Piso, Madrid, 2008. 
Derecho en la educación de los juristas, que ya comenté, y luego una suerte de reconocimiento sobre la incomprensión que rodea a dicha obviedad, y, a partir de ahí, la exposición sobre los argumentos que explican la necesidad de conservarla dentro de los planes de estudio de la Licenciatura en Derecho, así como de conservarle su estatuto como ciencia social. Ya nos advertía Fernando de Arvizú, ${ }^{8}$ desde la década de los ochenta, que los historiadores del Derecho teníamos cierta responsabilidad sobre esta incomprensión, y que debíamos asumirla y generar reflexión y resultados. Me parece que el espíritu de las aportaciones de Jaime Del Arenal, José Ramón Cossío, Rafael Estrada, Víctor Gayol, María Del Refugio González, Andrés Lira, Daniela Marino, Humberto Morales, David Pantoja, Carlos Ramos, María José Rhi Sausi, Elisa Speckman, Silvestre Villegas y, desde luego, Pablo Mijangos, es claramente una asunción plena de dicha responsabilidad y la interpreto, sobre todo, como una invitación, un reto para generar reflexiones científicas, pero también resultados prácticos en beneficio, no solo de la ciencia jurídica e histórica, sino de la sociedad a la que servimos. Y por ello, felicito a los autores y al coordinador de la obra, pero me congratulo aún más como lectora por el obsequio que sus autores nos han concedido.

Esta obra está bajo licencia internacional Creative Commons ReconocimientoNo-Comercial-CompartirIgual 4.0.

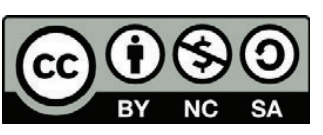

8 Arvizu y Galarraga, Fernando de, "La enseñanza de la historia del Derecho: reflexiones en busca de una polémica", Anuario de Historia del Derecho Español, 1988, pp. 491-498. 